cisiva de la. Reforma, los dilucidó con una penetración que está pidiendo continuadores. :El maestro Caso supo elegir, para este volumen, un panorama brillante y variado de las diversas disciplinas en que Sierra, en su tiempo, sentó escuela.

Antonio Acevedo Escobedo.

La sombra alucinante, Angélica Palma-Lima, C.I.P., 1938. 165 pp.

Este librito contiene, además de tuna carta dedicatoria a Pedro-Emilio Coll (por ser él quien le refirió el asunto de la primera novelita a doña Angélica Palma), dos novelas cortas. y un cuento, o sea "apuntito madrileño", según lo denomina la autora.

"La sombra alucinante" más parece bosquejo de novela que novela còta ni cucnto, lo cual se deberá al hecho de que la dejó inédita la escritora. El tema central es el efecto de una idea fija, concebida cuando era niño el protagonista Gastón, sobre la vida y el carácter de éste. Se repite la . idea a intervalos por medio del estribillo "Eres otro", hasta que, a fucrza de tanta repetición por distintas personas y del consiguiente creerlo Gastón, llega a parecer una especie de Doppelgänger literario que estorba, por su mera existencia asi como por sus escritos, la carrera del protagonista en el campo de las letras. Finalmente le llega a Gastón, por casualidad, la noticia de la muerte de sut rival.: Luego, liberado de su incubo, se siente vuelto a su propia individualidad, ya que "el otro" ha desaparecido (mejor dicho, desvanecido, porque es casi como si fuera figura creada de la obsesión, de la idea fija), y se despierta de su pesadilla, canaz aliora de trabajos hercúleos en el ambiente exultante de su anhelada soledad espiritual. Ya queda solo, solo...

Novela corta es "Al azar", aunque mucho más larga que las otras selecciones incluidas. En ella conocemos a la familia de Arteaga, a sus amigos y a sus parientes, y les acompañamos desde la Habana a Paris. Natural del Perú, la familia consta de tres personas: el padre, recientemente enriquecido, su. mujer, algo estúpida y muy impresionada por lo cle moda, $y$. su hija Alicia, muchacha aburrida a quien todo da lo mismo: El padre quiere casarla con un pariente suyo, vizconde español que se halla a la sazón en París. Pero se complica el progreso de tal plan con la presencia de un hombre tesuelto, de mucha experiencia mundana y de aspecto fino $y$ elegante, que se engracia con Alicia. Luego, llegados a Paris, alli seguimos:los vaivenes de todos los personajes hasta que; all firt, Alicia elige a uno 
de sus pretendientes al azar, porque aun esto de escoger marido a ella le "da lo mismo".

"Dos hipótesis", dedicado a doña Blanca de los Ríos, es el único cuento, propiamente dicho, de esta colección. Leyéndolo, vemos el contraste entre la vejez tranquila $y$ bella de doña Eugenia y la juventud efervescente $\mathrm{y}$ bulliciosa de su su sobrina Jenny, acompañada ésta de su hermana Amparo, más suave y soñadora, como indica su nombre. Se cvoca el recuerdo del único amor verdadero de la tía, amor sin consumación por haberse marchado el amado, pero que nunca se ha apagado en el tierno corazón de doña Eugenia. En efecto, tan vivo queda este amor que, al leer un día en el periódico la noticia de la muerte del ausente amado, muere la anciana. ¿De qué muere? Alí está el problema que resuelven las muchachas, cada cual a su manera de ver, of reciendo dos hipótesis.

Angélica Palma, en estas tres historias, se ha preocupado del retrato psicológico de varios personajes. En cuanto a Gastón y su idea fija, hay materia prima para una novela grande, que no corta, y probable es que la novelista haya pensado desarrollarla así. $\mathrm{Y}$ aunque no resulta malo el bosquejo en su forma actual, es lástima qué ella no haya tenido bastante tiempo para realizar tal plan.

En cuanto a Alicia, el resultado no justifica tanta extensión; su carácter, como queda pintado; pudiera caber dentro de unas pocas páginas. Es como si la escritora quisiera preséntar otros muchos caracteres vistos en la alta sociedad hispano-parisiensc, y por esto ha llenado de ellos las páginas de esta historia, rodeando a Alicia de una muchedumbre tan grande que casi casi se pierde a Alicia de vista. Su figura aparece, se hunde bajo la superficie de este oleaje de personas, y despućs de reaparecer de cuando en cuando, surge otra vez al final para cantar la última nota de su carácter esencialmente frivolo: "Da to mismo". Llena de escenas de la high life, del haut monde, y de otras expresioncs francesas c inglesas por el estilo, tantas quc, en fin, desvian la atención del lector, esta novelita tiene menor interés que "La sombra" y "Dos hipótesis". Y el fracaso se puede atribuir, en parte a lo menos, a la naturaleza del género, que no basta para retratar plenamente tantos personajes. Asi es que en vez de retratos tiene la novelita una colección de dibujos. Pero el argumento no vale para novela grande género dentro del cual se pudiera pintarlos mejor.

Sólo la tercera historia es obra pulida y acabada. Con relativamente pocas palabrás. la escritora nos ha dado la noble y suave figura de doña Eugenia, tain simpática, $y$ las de sus sobrinas, todas las tres dibujadas a to vivo, todas: movidas: por los tesortes naturales de stis personalidades, y un 
argumento senvillo, pero precisamente basta para llevar el asunto directamente al dénouemcnt. Con su unidad y su entereza, es un cuento, sin pretensiones a ser más, y por tanto resulta más digno de la pluma de la autora.

\section{L. Barret,}

Princeton University.

Cronología hercdiana (1803-1839), F. GonzÁlez del VAlle.-La Habana, Publicaciones de la Secretaría de Educación, Dirección de Cultura, 1938.

En mayo de 1939 se conmemoró el primer centenario de la muerte del gran poeta cubano don José Maria de Heredia y Campuzano. Las exposiciones de las obras y los manuscritos heredianos que se hicieron y las conferencias biográficas y criticas que se pronunciaron atrajeron de nuevo el pensaniento hacia este insigne lombre y escritor. Cont mayor atención y aprecio se han examinado su vida, su epistolario y sus poesias.

Entre las obras importantes que se han publicado recientemente sobre Heredia, se destaca cl libro de González del Valle. Se ofrece en él un valióso estudio de los muchos acontecimientos que lé ocurrieron al poeta desde su nacimiento en Santiago de Cuba en 1803 hasta su muerte en México, D. F., en 1839. Sus páginas presentan cxperiencias no limitadas tan sólo a las que tuvo en su patria y en México, sino a las que tuvo en Jamaica, Vénezuela y los Estadós Unidos, paises en donde se refugió a causa de las condiciones políticas existentes eñ Cuba.

La base de esta cronología, según lo explica el autor en su "Introducción", han sido los papeles heredianos pertenecientes al archivo de quien fué un ilustre bibliógrafo, don Domingo Figarola Caneda. Cón ellos se había propuesto escribir la viuda de Figarola Caneda un libro sobre el bardo cubano, pero la muerte frustró su plan; y sus papeles quedaron de légado a F. González del Valle, quien se decidió a publicarlos en forma le cronología, junto con algunos datos que él obtuvo como resultado de sus propias investigaciones:

Sienclo un verdadero erudito, reconoce González del Valle que la obra no es completa y definitiva: 'A pesar de la labor paciente y amorosa del antiguo Director de la Biblioteca Nacional de Cuba; don Domingo Figarola, y de la de su viuda, quedaba todavia algo por hacer sobre la amplia vida del autor del "Himno del desterrado". Sabe González del Valle que los esposos Figarola Caneda no: se habian enterado de los últimos datos he- 
sedianos conseguidos por José María Chacón y Calvo, Enrique Larrondo, Nicolás Rangel y José de J. Núñez Domínguez. Opina que tampoco habian consultado las cartas de Heredia existentes en algunas bibliotecas de la Habara. En cambio, afirma que habian hecho largas y difíciles pesquisas en los Estados Unidos, México y España.

González del Valle se ha ocupado en llenar estas lagunas. Escribió la "Introducción" de esta Cronología herediana hace varios años y la hizo publicar en la "Revista Bimestre Cubana" (julio-octubre, 1933). Desde entonces buscó con grande ahinco importantes hechos relacionados con Heredia en los Archivos Nacionales, y obtuvo de sus amigos algunos documentos $y$ obras raras y agotadas.

Al presentar los papeles pertenecientes a los esposos Figarola Caneda y el resultado de sus propias investigaciones, ha obrado con sumo cuidado. $\mathrm{Ha}$ anotado cada hecho con las mejores citas y referencias, sirviéndose de las cartas de Heredia y de los juicios criticos y biográficos publicados en vida del poeta. Ha puestc en forma clara y disponible una gran cantidad de datos sobre el Cantor del Niágara, y ha hecho valiosas e interesantes contribuciones.

Con suma modestia este infatigable erudito espera que otros investigadores de la vida del poeta rectifiquen y adicionen su trabajo. Plantea claramente algunos problemas que no están resueltos todavia. Deseà que salga pronto de México la solución de algunos de ellos, por ser alli donde se dieron a la luź pública los principales escritos politicos y literarios de Heredia, cntre 1825 y 1839 , y le pide al culto historiografo mexicano don Arturo Arnáiz y Freg, autor de un interesante artículo sobre el primer centenario de la muerte de Heredia - publicado en el primer número de la REVISTA IBEROAMERICANA- que publique los papeles que él posee $y$ desconoce el público.

Los aniantes de la "Oda al Niágara" quedamos agradecitos a don Francisco González del Valle por habernos facilitado el estudio de todos los aspectos de la insigne personalidad de su autor, y esperamos con ansia genuina la publicación de otras obras suyzs sobre el primer poeta del Parnaso Cubano.

Esther J. Crooks, Goucher College, Baltimore, Maryland. 